\title{
Grave thoraco-intestinal complication secondary to an undetected traumatic rupture of the diaphragm: a case report
}

\author{
Morris Beshay ${ }^{1 \dagger}$, Martin Krüger ${ }^{2 \dagger}$, Kashika Singh ${ }^{3}$, Rainer Borgstedt ${ }^{4}$, Tahar Benhidjeb ${ }^{3}$, Edwin Bölke $^{5}$ (D, \\ Thomas Vordemvenne ${ }^{6+}$ and Jan Schulte am Esch ${ }^{3,7^{*+}}$
}

\begin{abstract}
Background: Diaphragmatic lesions as a result of blunt or penetrating trauma are challenging to detect in the initial trauma setting. This is especially true when diaphragmatic trauma is part of a polytrauma. Complications of undetected diaphragmatic defects with incarcerating bowel are rare, but as in our patient can be serious.

Case presentation: A 57-year-old female presented to the Emergency Room of our Hospital in a critical condition with 3 days of increasing abdominal pain. The initial clinical examination showed peritonism with tinkling peristaltic bowel sounds of mechanical obstruction. A thoraco-abdominal CT scan demonstrated colon prolapsed through the left diaphragmatic center with a large sero-pneumothorax under tension. As the patient was hemodynamically increasingly unstable with developing septic shock, an emergency laparotomy was performed. After retraction of the left colon, which had herniated through a defect of the tendinous center of the left diaphragm and was perforated due to transmural ischemia, large amounts of feces and gas discharged from the left thorax. A left hemicolectomy resulting in a Hartmann-type procedure was performed. A fully established pleural empyema required meticulous debridement and lavage conducted via the $7-10 \mathrm{~cm}$ in diameter phrenic opening followed by a diaphragmatic defect reconstruction. Due to pneumonia and recurring pleural empyema redo-debridement of the left pleural space via thoracotomy were required. The patient was discharged on day 56. A thorough history of possible trauma revealed a bicycle-fall trauma 7 months prior to this hospitalization with a surgically stabilized fracture of the left femur and conservatively treated fractures of ribs 3-9 on the left side.
\end{abstract}

Conclusion: This is the first report on a primarily established empyema at the time of first surgical intervention for feco-pneumothorax secondary to delayed diagnosed diaphragmatic rupture following abdomino-thoracic blunt trauma with colic perforation into the pleural space, requiring repetitive surgical debridement in order to control local and systemic sepsis. Thorough investigation should always be undertaken in cases of blunt abdominal and thoracic trauma to exclude diaphragmatic injury in order to avoid post-traumatic complications.

Keywords: Bowel perforation, Pneumothorax, Herniation, Diaphragmatic rupture, Pleural empyema, Case report

*Correspondence: jan.schulteamesch@evkb.de

${ }^{\dagger}$ Morris Beshay and Martin Krüger contributed equally

†Thomas Vordemvenne and Jan Schulte am Esch contributed equally ${ }^{7}$ Department of General and Visceral Surgery, Evangelisches Klinikum Bethel, Schildescher Str. 99, 33611 Bielefeld, Germany

Full list of author information is available at the end of the article

\section{Background}

The incidence of traumatic diaphragmatic rupture in trauma patients is about $0.5 \%$ [1]. With $80 \%$ of those cases, the left side is predominantly involved, with twothirds of the cases subsequent to penetrating injuries and the remaining as a result of blunt trauma $[1,2]$. Up to $3 \%$ of abdominal traumas include diaphragmatic tears that

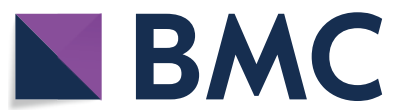

(c) The Author(s) 2021. This article is licensed under a Creative Commons Attribution 4.0 International License, which permits use, sharing, adaptation, distribution and reproduction in any medium or format, as long as you give appropriate credit to the original author(s) and the source, provide a link to the Creative Commons licence, and indicate if changes were made. The images or other third party material in this article are included in the article's Creative Commons licence, unless indicated otherwise in a credit line to the material. If material is not included in the article's Creative Commons licence and your intended use is not permitted by statutory regulation or exceeds the permitted use, you will need to obtain permission directly from the copyright holder. To view a copy of this licence, visit http://creativeco mmons.org/licenses/by/4.0/. The Creative Commons Public Domain Dedication waiver (http://creativecommons.org/publicdomain/ zero/1.0/) applies to the data made available in this article, unless otherwise stated in a credit line to the data. 
bear a diagnostic challenge as they can only reliably be ruled out with direct visualization via laparo- or thoracoscopy and remain primarily undetected in $50 \%$ of cases [3-5]. Although prolapse of intestinal content at the site of the traumatic diaphragmatic hernia is a known presentation, severe forms are rare.

\section{Case presentation}

A 57-year-old female presented to the Emergency Room in a critical condition, severe abdominal pain (NRS $8 / 10$ ), diarrhea, nausea without vomiting or dyspnea. Abdominal pain was present for 3 days, initially intermittent and colicky changing to a constant and sharp quality with increasing intensity. She reported no comorbidity and a hysterectomy 29 years ago. The initial clinical examination showed the following findings: the patient was hemodynamically increasingly unstable with marbled skin color. Peritonism was present with tinkling peristaltic bowel sounds of mechanical obstruction. The patient was in a septic shock with severe lactate acidosis $(9.5 \mathrm{mmol} / \mathrm{l} ; \mathrm{pH} 7.279)$, a base excess of $-16.0 \mathrm{mmol} / \mathrm{L}$ and an $\mathrm{O}_{2}$-saturation of $84 \%$ prior to receiving high flow oxygen. Further laboratory testing revealed elevated creatinine $(3.0 \mathrm{mg} / \mathrm{dl})$, increased C-reactive protein (407.9 mg/l, ref.: < 5), interleukin- 6 of $14,864.0 \mathrm{pg} / \mathrm{ml}$ and a procalcitonin of $37.1 \mathrm{ng} / \mathrm{ml}$. E. coli was subsequently detected in blood cultures. CT scan revealed prolapsed colon through the left diaphragmatic center with seropneumothorax under tension (Fig. 1a-c). While preparing for emergency laparotomy, the patient had a cardiac arrest requiring CPR for $5 \mathrm{~min}$. An immediate laparotomy and retraction of the splenic flexure and left colon, which herniated through a defect of the tendinous center of the left diaphragm accompanied by a perforation due to transmural ischemia, was performed. Two liters of feces and a large amount of gas were evacuated from the left thorax. A left hemicolectomy with an end transverse colostomy and sigmoid closure resulting in a Hartmanntype procedure was performed. Rigorous pleural lavage via the traumatic tear of 7-10 cm in diameter unmasked an empyema with a pleural membranous thickening of up to $8 \mathrm{~mm}$. Meticulous debridement of the lower lobe and caudal parts of the upper lobe trans-diaphragmatically was conducted via the diaphragmatic opening was followed by a defect reconstruction with a woven running suture in two rows. Subsequently, the reconstructed diaphragm stayed intact for the total clinical course as revealed by chest X-ray examination on postoperative day 3 (Fig. 2). Due to pneumonia and recurring pleural empyema in the course of a prolonged ICU-stay, repetitive bronchoscopies and two redo debridements of the left pleural cavity via open thoracotomy were required. Weaning of ventilation was supported by temporary tracheostomy. A wound infection of the laparotomy wound was managed with vacuum dressing followed by secondary closure. The patient was discharged on day 56 . A thorough history of possible trauma revealed a bicyclefall trauma 7 months prior to this hospitalization with a fracture of the left femur, stabilized by internal fixation, and conservatively treated fractures of ribs 3-9 on the left side.

\section{Discussion and conclusion}

Feco-pneumothorax due to perforation of diaphragmatically herniated colon to the pleural cavity is a rare entity, and frequently associated with a tension pneumothorax unmasking the diaphragmatic lesion weeks to decades after the initially undetected injury $[6,7]$. Nine of a total of 16 cases previously reported were secondary to perforating chest injuries [3, 6, 8-14], whereas the remaining seven cases had a history of blunt abdominal and/ or thoracic injury as happened to our patient $[4,7,15-$ 19]. Empyema is a complication that can develop in the course of these patients, requiring secondary drainage or interventional debridement and is still associated with a mortality of $25-66 \%$ [3, 4]. Our patient is the second case of a primarily established empyema at the time of first surgical intervention out of a total of eight reported cases with feco-pneumothorax secondary to delayed diagnosed diaphragmatic rupture following abdomino-thoracic blunt trauma with colic perforations to the pleural space, the first reported in 1981 [7]. Further, it is the first case in that cohort requiring repetitive surgical debridement in order to control local and systemic sepsis.

Our patient had a rare and life-threatening variant of a delayed intestinal complication following an initially undetected traumatic diaphragmatic rupture. The diagnosis of traumatic diaphragmatic injury is usually challenging, even if a secondary or even third diagnostic survey according to ATLS principles is obtained. Therefore, thorough investigation should always be undertaken in cases of blunt abdominal and thoracic trauma to exclude diaphragmatic injury. In order to avoid overlooking such traumatic complication, both radiologists and surgeons should be familiar with the variety of changes potentially indicating diaphragm rupture, such as diaphragm discontinuity, collar sign, herniation, gas and fluid shadowing in the thoracic space, atelectasis in the lower lobes and dependent viscera sign like elevated abdominal organs $[20,21]$. Further signs indicative for advanced or complicated diaphragmatic ruptures on pulmonary radiographs are pleural effusion, pneumothorax, hydro-pneumothorax and mediastinal shift, as observed for our patient.

The defect was a grade III of V according to "The Organ Injury Scaling Committee of the American Association 

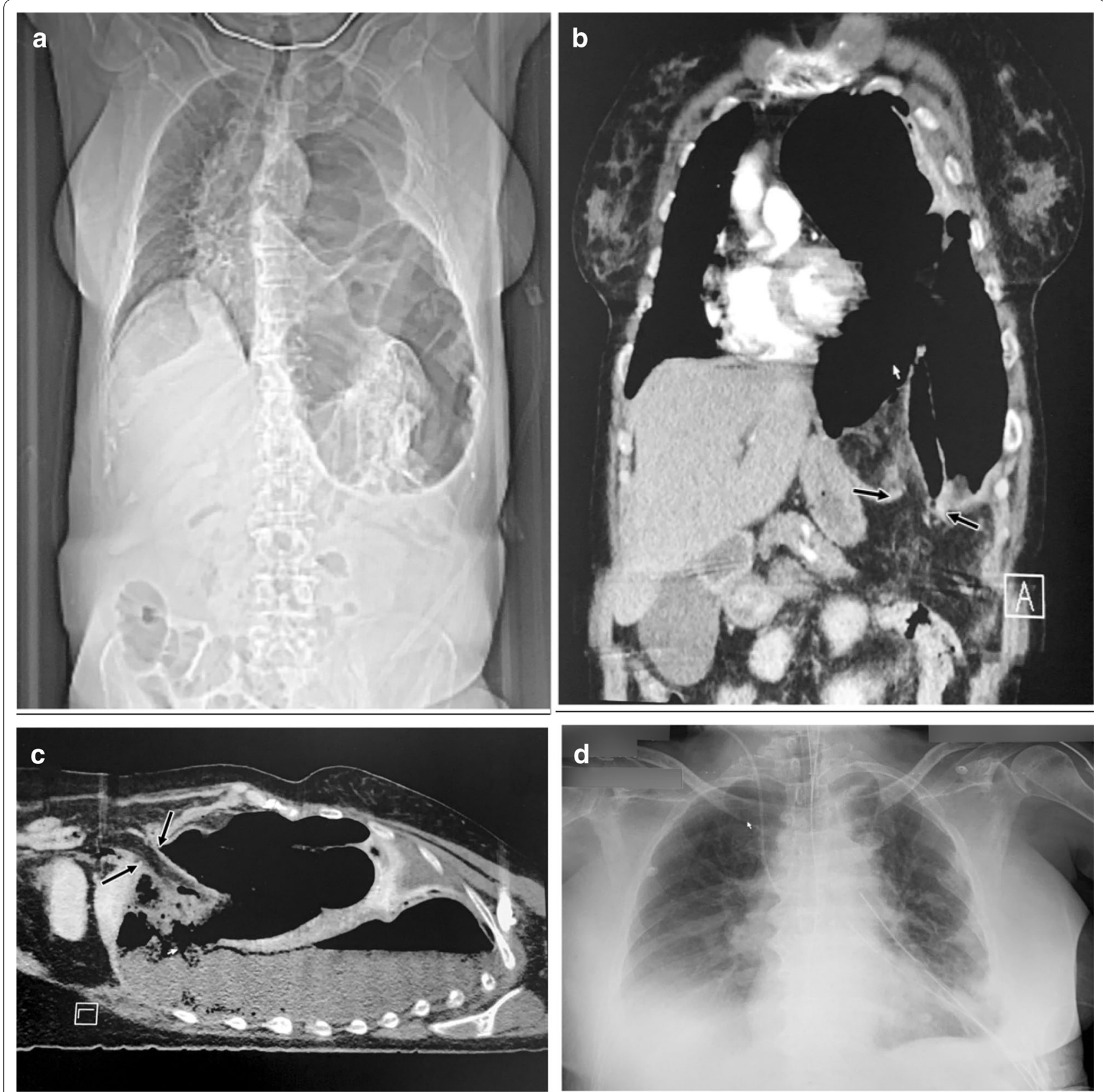

Fig. 1 Radiological imaging on day of admission. Thoraco-abdominal CT scan with localizer of carried out CT scan (a) and representative CT scan images (b, c): enterothorax with splenic flexure prolapse through an old undetected traumatic rupture of the left diaphragmatic center, consecutive colic incarceration ( $\mathbf{b}+\mathbf{c}$; arrows) with ischemia, rupture of the colon into the left pleural cavity with feco-pneumothorax under tension, cardiac depression due to mediastinal shift to the right and sepsis secondary to left pleural empyema (c), inversed diaphragm and midline shift to the right $(\mathbf{a}+\mathbf{b})$. Post-surgical chest X-ray examination $(\mathbf{d})$ : re-expanded left lung and reversal of the mediastinal shift with reconstructed diaphragm

for the Surgery of Trauma" as in the range of $2-10 \mathrm{~cm}$ length [22]. We selected a double-layer running suture, as advocated also by others for these sized defects of the ruptured diaphragm [1]. Although no larger or randomized trials are available on diaphragmatic reconstruction subsequent to trauma, recommendations range from monofilament non-absorbable or absorbable interrupted sutures for small defects of up to $6 \mathrm{~cm}$ to interrupted figure-of-eight or interlocking mattress sutures for larger defects. Rarely, there may be an indication for a prosthetic mesh for the larger defects [1]. The access can be abdominal, combined abdomino-thoracic or thoracic 

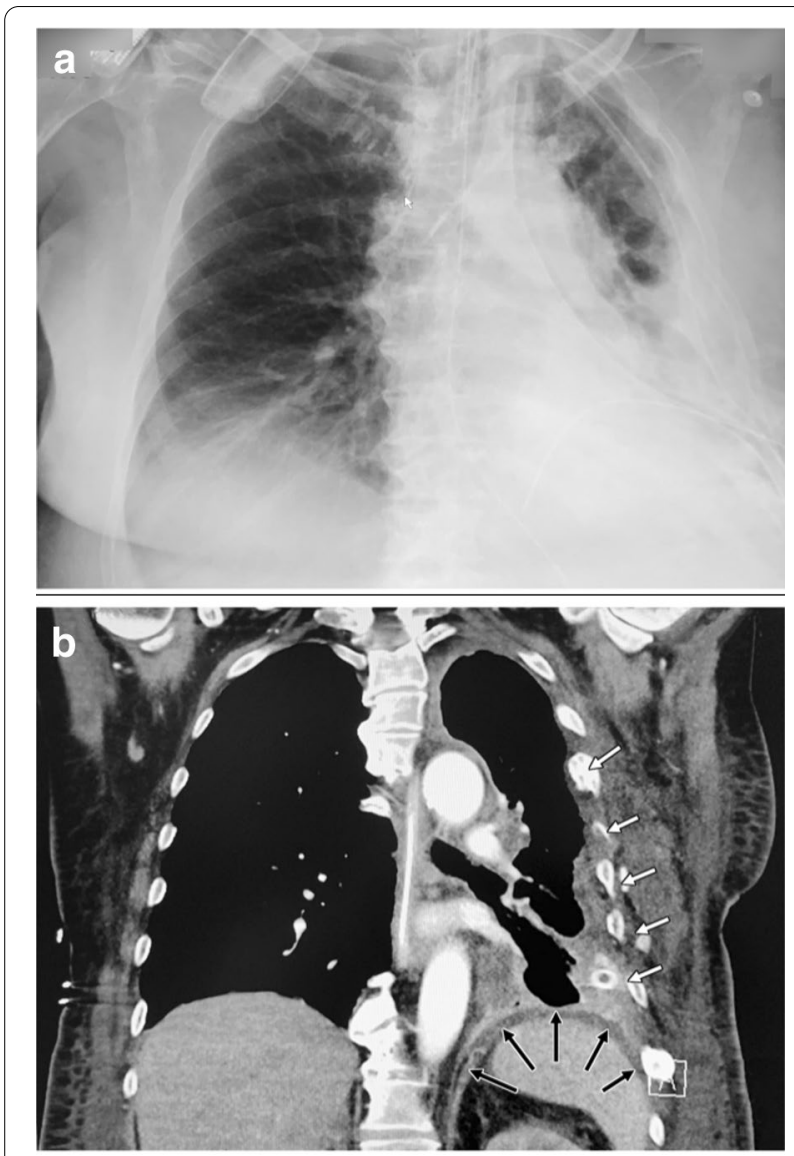

Fig. 2 Radiological imaging on day 20. Chest X-ray examination (a) and thoraco-abdominal CT scan (b): reaccumulation of the left pleural empyema. The diaphragm stayed intact (black arrows) over the whole clinical course subsequent to reconstruction during initial surgery on day 1 . White arrows indicate remnants of the healed rib fractures as a consequence of the bicycle trauma 7 months prior to admission for feco-pneumothorax

only, depending on the individual strategy and pattern of injuries. In our case, abdominal access was justified for the primary intervention.

Our strategy for treating postoperative recurrent empyema was based on three main principles: (1) broad spectrum antibiotics as early as possible; (2) complete surgical debridement and lavage with or without vacuum application, and (3) early mobilization and bronchial lavage. In accordance to the literature, we followed this very successful concept for the effective management of this patient's postoperative empyema [23].

The severity of this patient's condition illustrates the vital importance of early diagnosis of diaphragmatic ruptures following thoraco-abdominal trauma. Further, the importance of this report is to demonstrate that an interdisciplinary treatment strategy involving diverse medical and surgical expertise is required, including rigorous ongoing pleural and bronchial management in order to obtain the optimum outcome.

\section{Acknowledgements}

We are indebted to Dr. Matthew Tytherleigh, consultant general surgeon, for his invaluable contribution in editing the manuscript with regard to English language and consistency.

\section{Authors' contributions}

MB: acquisition of data; drafting of the manuscript. MK: acquisition of data; critical revision of the manuscript. KS: data analysis, revision of the manuscript. RB: analysis and interpretation of data. TB: critical revision of the manuscript for important intellectual content. EB: analysis and interpretation of data. TV: analysis and interpretation of data. JSaE: concept and design; critical revision of the manuscript for important intellectual content. All authors have read and approved the manuscript.

\section{Funding}

Open Access funding enabled and organized by Projekt DEAL.

\section{Availability of data and materials}

The data generated during and/or analyzed during the current case report are available from the corresponding author on reasonable request.The data generated during and/or analyzed during the current case report are available from the corresponding author on reasonable request.

\section{Ethics approval and consent to participate}

According to local ethical regulations (Ethics committee of the Heinrich Heine University, Düsseldorf, Germany) "case reports are not prospectively planned research projects on or with people, but retrospective case descriptions of medical actions. Therefore, the ethics committee is not responsible for evaluating case reports" and consequently is waiving the necessity of an ethical approval for case reports.

\section{Consent for publication}

Written informed consent for publication was obtained from the patient.

\section{Competing interests}

No competing interests or conflicts exist for any author to declare.

\section{Author details}

${ }^{1}$ Department of Thoracic Surgery, University Hospital OWL of the University Bielefeld, campus Bielefeld-Bethel, Bielefeld, Germany. ${ }^{2}$ Department of Internal Medicine and Gastroenterology, University Hospital OWL of the University Bielefeld, campus Bielefeld-Bethel, Bielefeld, Germany. ${ }^{3}$ Department of General and Visceral Surgery, University Hospital OWL of the University Bielefeld, campus Bielefeld-Bethel, Bielefeld, Germany. ${ }^{4}$ Department of Anesthesiology, Intensive Care, Emergency-, Transfusion- and Pain-Medicine, University Hospital OWL of the University Bielefeld, campus Bielefeld-Bethel, Bielefeld, Germany. ${ }^{5}$ Medical Faculty, Department of Radiation Oncology, Heinrich Heine University, Duesseldorf, Germany. ${ }^{6}$ Department of Trauma Surgery and Orthopedics, University Hospital OWL of the University Bielefeld, campus Bielefeld-Bethel, Bielefeld, Germany. ${ }^{7}$ Department of General and Visceral Surgery, Evangelisches Klinikum Bethel, Schildescher Str. 99, 33611 Bielefeld, Germany.

Received: 19 November 2020 Accepted: 23 January 2021

Published online: 08 February 2021

\section{References}

1. Furak J, Athanassiadi K. Diaphragm and transdiaphragmatic injuries. J Thorac Dis. 2019;11(Suppl 2):S152-7.

2. Lim BL, Teo LT, Chiu MT, Asinas-Tan ML, Seow E. Traumatic diaphragmatic injuries: a retrospective review of a 12-year experience at a tertiary trauma centre. Singapore Med J. 2017;58(10):595-600.

3. Khan MA, Verma GR. Traumatic diaphragmatic hernia presenting as a tension fecopneumothorax. Hernia. 2011;15(1):97-9. 
4. Jarry J, Razafindratsira T, Lepront D, Pallas G, Eggenspieler P, Dastes FD. Tension faecopneumothorax as the rare presenting feature of a traumatic diaphragmatic hernia. Ann Chir. 2006;131(1):48-50.

5. Chughtai T, Ali S, Sharkey P, Lins M, Rizoli S. Update on managing diaphragmatic rupture in blunt trauma: a review of 208 consecutive cases. Can J Surg. 2009;52(3):177-81

6. Kelly J, Condon E, Kirwan W, Redmond H. Post-traumatic tension faecopneumothorax in a young male: case report. World J Emerg Surg. 2008:3:20.

7. Hussain SA, Suriyapa C, Grubaugh K. Intra-thoracic and intra- abdomina perforation of the colon in traumatic diaphragmatic hernia. J Pak Med Assoc. 1981;31(1):14-6.

8. Chern TY, Kwok A, Putnis S. A case of tension faecopneumothorax after delayed diagnosis of traumatic diaphragmatic hernia. Surg Case Rep. 2018;4(1):37.

9. Popentiu Al, Weber-Lauer C, Nieman C, Kauvar DS, Sabau D. Late presentation of a shrapnel wound-induced traumatic intra-thoracic abdominal evisceration, as colon perforation with left faecopneumothorax. Chirurgia. 2010;105(2):253-6.

10. Ramdass MJ, Kamal S, Paice A, Andrews B. Traumatic diaphragmatic herniation presenting as a delayed tension faecopneumothorax. Emerg Med J. 2006;23(10):e54.

11. Vermillion JM, Wilson EB, Smith RW. Traumatic diaphragmatic hernia presenting as a tension fecopneumothorax. Hernia. 2001;5(3):158-60.

12. Seelig MH, Klingler PJ, Schönleben K. Tension fecopneumothorax due to colonic perforation in a diaphragmatic hernia. Chest. 1999;115(1):288-91.

13. Reddy SA, Vemuru R, Padmanabhan K, Steinheber FU. Colopleural fistula presenting as tension pneumothorax in strangulated diaphragmatic hernia. Report of a case. Dis Colon Rectum. 1989;32(2):165-7.

14. Phipps RF, Jackson BT. Faeco-pneumothorax as the presenting feature of a traumatic diaphragmatic hernia. J R Soc Med. 1988;81(9):549-50.
15. Abdullah M, Stonelake P. Tension pneumothorax due to perforated colon BMJ Case Rep. 2016. https://doi.org/10.1136/bcr-2016-215325.

16. Ozkan OV, Semerci E, Yetim I, Davran R, Diner G, Paltaci I. Delayed diagnosis of traumatic diaphragmatic hernia may cause colonic perforation: a case report. Cases J. 2009;2:6863.

17. Kafih M, Boufettal R. A late post-traumatic diaphragmatic hernia revealed by a tension fecopneumothorax (a case report). Rev Pneumol Clin. 2009;65(1):23-6.

18. Montresor E, Bortolasi L, Modena S, Ragni E, Attino M, Mangiante G, Mainente M, Puchetti V. Delayed traumatic hernia of the diaphragm presenting with hypertensive pneumothorax. Case report and review of the literature. G Chir. 1997;18(5):295-6.

19. Baltasar A. Post-traumatic diaphragmatic hernia with complete pneumothorax caused by colonic perforation. Rev Clin Esp. 1976;141(1):93-6.

20. Liu J, Yue WD, Du DY. Multi-slice computed tomography for diagnosis of combined thoracoabdominal injury. Chin J Traumatol. 2015;18(1):27-32.

21. Tokgoz S, Akkoca M, Ucar Y, Yilmaz KB, Sevim O, Gundogan G. Factors affecting mortality in traumatic diaphragm ruptures. Ulus Travma Acil Cerrahi Derg. 2019;25(6):567-74.

22. Moore EE, Malangoni MA, Cogbill TH, Shackford SR, Champion HR, Jurkovich GJ, McAninch JW, Trafton PG. Organ injury scaling. IV: thoracic vascular, lung, cardiac, and diaphragm. J Trauma. 1994;36(3):299-300.

23. Scarci M, Abah U, Solli P, Page A, Waller D, van Schil P, Melfi F, Schmid RA Athanassiadi K, Sousa Uva M, et al. EACTS expert consensus statement for surgical management of pleural empyema. Eur J Cardiothorac Surg. 2015;48(5):642-53.

\section{Publisher's Note}

Springer Nature remains neutral with regard to jurisdictional claims in published maps and institutional affiliations.
Ready to submit your research? Choose BMC and benefit from:

- fast, convenient online submission

- thorough peer review by experienced researchers in your field

- rapid publication on acceptance

- support for research data, including large and complex data types

- gold Open Access which fosters wider collaboration and increased citations

- maximum visibility for your research: over $100 \mathrm{M}$ website views per year

At BMC, research is always in progress.

Learn more biomedcentral.com/submissions 